\title{
Automated Irrigation System using Wireless Sensor Network and Raspberry Pi
}

\author{
Suprabha Jadhav ${ }^{1}$, Shailesh Hambarde ${ }^{2}$ \\ ${ }^{1}$ Savitribai Phule Pune University, JSPM's JSCOE, Handewadi Road, Hadapsar, Pune-28, India \\ ${ }^{2}$ Savitribai Phule Pune University, JSPM's JSCOE, Handewadi Road, Hadapsar, Pune-28, India
}

\begin{abstract}
An automated irrigation system was developed to optimize water use for agricultural crops. The system has a distributed wireless network of soil-moisture, humidity and temperature sensors. As the technology is growing and changing rapidly, Wireless sensing Network (WSN) helps to upgrade the technology where automation is playing important role in human life. Automation allows us to control appliances automatically. It not only provides comfort but also reduce energy, increases efficiency and it is saves time. The objectives of this paper were to control the water motor automatically, monitor the plant growth using various parameters, spray fertilizers if needed and also develop an android app. The main idea of this is to understand how data travels through a wireless medium transmission using wireless sensor network and monitoring system.
\end{abstract}

Keywords: Raspberry pi, Android app, Automation, Wireless Sensor Networks (WSNs)

\section{Introduction}

India is the largest freshwater user in the world, and the country's total water use is greater than any other continent. The agricultural sector is the biggest user of water, followed by the domestic sector and the industrial sector. Groundwater contributes to around $65 \%$ of the country's total water demand, and plays an important role in shaping the nation's economic and social development.

On the other hand, feeding country's own population, which is $17 \%$ of the world with just $4 \%$ of world's water resources at hand, is a big challenge. Balancing water demand among all sectors with finite and fragile water resources will be crucial for future economic growth and development.

As water demand from cities and industries is increasing rapidly, pressure is also mounting on agriculture to enhance water efficiency. Traditional irrigation methods are no longer viable and a paradigm shift is required to increase irrigation efficiency. With around two third of Indians depend upon agrarian economy, water is becoming a bottleneck for country's socio-economic balance and growth.

As water demand management measure in agriculture, recently a micro-irrigation technology, which mainly includes drip and sprinkler irrigation methods have been introduced. Unlike conventional flood irrigation, water in this method is supplied at a required interval and quantity using piped network, emitters and nozzles. Thus, the conveyance and distribution losses are reduced which results into higher water use efficiency. Minimizing water use also reduces energy use for pumping groundwater.

An irrigation controller is used to open a solenoid valve and apply watering to plants when the volumetric water content of the substrate drops below a set point. Automatic irrigation scheduling consistently has shown to be valuable in water use efficiency with respect to manual irrigation based on direct soil water measurements.

\section{Literature Review}

After the research in the agricultural field, researchers found that the yield of agriculture goes on decreasing day by day. Use of technology in the field of agriculture plays important role in increasing the production as well as in reducing the extra man power efforts, water requirement and fertilizer requirement.

A prototype for fully automation accessing of irrigation motor where Prototype includes number of sensor node placed in different directions of farm field. Each sensor is integrated with a wireless networking device and the data received by the "ATMEGA-328" microcontroller which is on a "ARDUINO-UNO" development board. The RASPBERRYPi is use for send messages through internet correspondence to the microcontroller process [1].

There are many systems to achieve water savings in various crops, from basic ones to more technologically advanced ones. For instance, in one system plant water status was monitored and irrigation scheduled based on canopy temperature distribution of the plant, which was acquired with thermal imaging [2].

In addition, other systems have been developed to schedule irrigation of crops and optimize water use by means of a crop water stress index (CWSI) [3].

Irrigation systems can also be automated through information on volumetric water content of soil, using dielectric moisture sensors to control actuators and save water, instead of a predetermined irrigation schedule at a particular time of the day and with a specific duration. An irrigation controller is used to open a solenoid valve and apply watering to bedding plants (impatiens, petunia, salvia, and vinca) when the volumetric water content of the substrate drops below a set point [4].

Other authors have reported the use of remote canopy temperature to automate cotton crop irrigation using infrared 


\section{International Journal of Science and Research (IJSR) \\ ISSN (Online): 2319-7064}

Index Copernicus Value (2013): 6.14 | Impact Factor (2014): 5.611

thermometers. Through a timed temperature threshold, automatic irrigation was triggered once canopy temperatures exceeded the threshold for certain time accumulated per day. Automatic irrigation scheduling consistently has shown to be valuable in optimizing cotton yields and water use efficiency with respect to manual irrigation based on direct soil water measurements [5].

In Florida, automated switching tensiometers have been used in combination with ET calculated from historic weather data to control automatic irrigation schemes for papaya plants instead of using fixed scheduled ones. Soil water status and ET-based irrigation methods resulted in more sustainable practices compared with set schedule irrigation because of the lower water volumes applied [6].

\section{Proposed System}

The block diagram of the proposed system as shown in Fig. 1 consists of different types of sensing unit such as Soil Moisture Sensor to measure water content of soil, Temperature Sensor detects the temperature, Humidity Sensor to measure the presence of water in air.

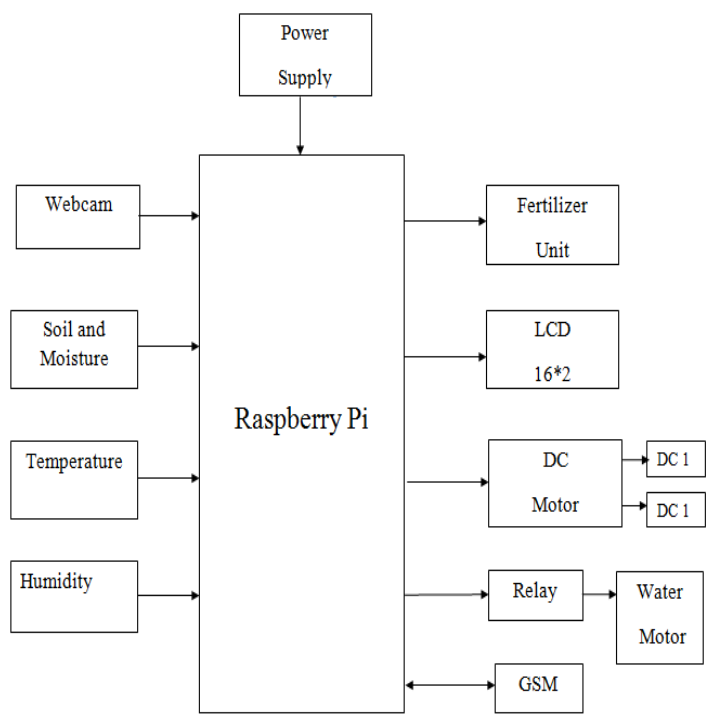

Figure 1: Propsed system design

\subsection{Components Description:}

\subsubsection{Power Supply:}

One of the most exciting updates/upgrades of the new Model $\mathrm{B}+$ is a fancy new power supply. The power supply is what takes the micro USB port voltage and creates the $5 \mathrm{~V}$ USB, $3.3 \mathrm{~V}, 2.5 \mathrm{~V}$ and $1.8 \mathrm{~V}$ core voltages. The $3.3 / 2.5 / 1.8$ are for the processor and Ethernet.

\subsubsection{Sensors:}

Sensors are the device which converts the physical parameter into the electric signal. The system consists of temperature, humidity, moisture, soil $\mathrm{pH}$ and soil nitrogen sensor. The output of sensor is analog signal; the signal is converted into digital signal and then fed to the processor. The temperature sensor is used to measure the temperature of the soil. Here
LM35 temperature sensor is used. The output voltage of sensor is linearly proportional to the Celsius (Centigrade) temperature. The humidity sensor is used to measure the environment humidity. SY-HS-220 is used as a humidity sensor module. The relative humidity is converted to the output voltage which is the required output. The moisture sensor is used to measure the moisture content of the soil. Copper electrodes are used to sense the moisture content of soil. The conductivity between the electrodes helps to measure the moisture content level.

\subsubsection{Raspberry-Pi}

The Raspberry Pi is a small, powerful and lightweight ARM based computer which can do many of the things a desktop PC can do. The powerful graphics capabilities and HDMi video output make it ideal for multimedia applications such as media centers and narrowcasting solutions. The Raspberry Pi is based on a Broadcom BCM2835 chip. It does not feature a built-in hard disk or solid-state drive, instead relying on an SD card for booting and long-term storage.

\subsection{Proposed System Working}

There are 2 modes of operation:

a. Manual Mode

b. Automatic Mode

In this project, webcam is interfaced to Raspberry Pi via WiFi module. Here the raspberry Pi takes snapshot wirelessly using Mobile camera. Then Rasp berry Pi will do image processing to find out the soil color samples. According to soil samples the Pi will send the information to user on the android app regarding the soil and seeds / crops which can be used on this type of soil.

Furthermore, DC motor based vehicle is designed. The camera is mounted on the vehicle. The vehicle is stopped in front of a crop / plant. Soil and moisture electrodes will be inserted in soil. If electrode is not fully immersed in the soil due to any obstacle, the vehicle will move further and repeat the process unless and until the electrodes are not fully immersed.

Once immersed, the moisture contents will be checked. If inadequate then water will be supplied to that particular plant. Also depending on the values of temperature and humidity sensors, the water motor will be turned on an off respectively.

This process will be repeated for all the plants. The Pi will also take snapshots of the plant for intervals of few days and calculate the growth of plant using the height and width parameters. If the plant growth is adequate then $\mathrm{Pi}$ will continue the process for next plants. If the growth is insufficient then Pi will spray fertilizer o the plant and send an indication to user on android app.

Also Android App based server is designed as part of this project. The android app will have a GUI which will show all the data to user. The modes as specified can be selected by the user on the app itself.

\section{Volume 4 Issue 12, December 2015}




\section{International Journal of Science and Research (IJSR) \\ ISSN (Online): 2319-7064}

Index Copernicus Value (2013): 6.14 | Impact Factor (2014): 5.611

In manual mode, the DC motor based vehicle will move ahead with the fixed distance as it will be assumed that plants are present at same distance. In automatic mode, the user will be able to move the vehicle forward, reverse or left and right through app. This can be done within range of $30 \mathrm{~m}$ as it is done using $\mathrm{Wi}-\mathrm{Fi}$.

\section{Advantages}

- Fertilizer and nutrient loss is minimized due to localized application and reduced leaching.

- Water application efficiency is high if managed correctly

- Field levelling is not necessary.

- Fields with irregular shapes are easily accommodated.

- Recycled non-potable water can be safely used.

- Moisture within the root zone can be maintained at field capacity.

- Soil type plays less important role in frequency of irrigation.

- Soil erosion is lessened.

- Water distribution is highly uniform, controlled by output of each nozzle.

- Labour cost is less than other irrigation methods.

- Variation in supply can be regulated by regulating the valves and drippers.

- Fertigation can easily be included with minimal waste of fertilizers.

\section{Conclusion}

The automated irrigation system that will be implemented would be feasible and cost effective for optimizing water resources for agricultural production. The system would provide feedback control system which will monitor and control all the activities of drip irrigation system efficiently.

This irrigation system will allow cultivation in places with water scarcity thereby improving sustainability. Using this system, one can save manpower, water to improve production and ultimately increase profit.

\section{References}

[1] Chandankumar Sahu, Pramitee Behera, "A Low Cost Smart Irrigation Control System", IEEE Sponsored 2nd International Conference on Electronics and Communication System (ICECS 2015)

[2] X. Wang, W. Yang, A. Wheaton, N. Cooley, and B. Moran, "Efficient registration of optical and IR images for automatic plant water stress assessment," Comput. Electron. Agricult., vol. 74, no. 2, pp. 230-237, Nov. 2010.

[3] G. Yuan, Y. Luo, X. Sun, and D. Tang, "Evaluation of a crop water stress index for detecting water stress in winter wheat in the North China Plain," Agricult. Water Manag., vol. 64, no. 1, pp. 29-40, Jan. 2004.

[4] K. S. Nemali and M. W. Van Iersel, "An automated system for controlling drought stress and irrigation in potted plants," Sci. Horticult., vol. 110, no. 3, pp. 292 297, Nov. 2006
[5] S. A. O'Shaughnessy and S. R. Evett, "Canopy temperature based system effectively schedules and controls center pivot irrigation of cotton," Agricult. Water Manag., vol. 97, no. 9, pp. 1310-1316, Apr. 2010.

[6] K. W. Migliaccio, B. Schaffer, J. H. Crane, and F. S. Davies, "Plant response to evapotranspiration and soil water sensor irrigation scheduling methods for papaya production in south Florida," Agricult. Water Manag., vol. 97 , no. 10 , pp. $1452-1460$, Oct. 2010 